\title{
Adhesive properties of carcinoembryonic antigen glycoforms expressed in glycosylation-deficient Chinese hamster ovary cell lines ${ }^{\star}$
}

\author{
Anna Krop-Watorek ${ }^{\varpi}$, Arkadiusz G. Klopocki, Marcin Czerwinski and \\ Elwira Lisowska
}

\section{Department of Immunochemistry, Ludwik Hirszfeld Institute of Immunology and Experimental Therapy, Polish Academy of Sciences, Wroctaw, Poland}

Received: 11 October, 2001; revised: 21 January, 2002, accepted: 2 February, 2002

Key words: carcinoembryonic antigen, N-glycoforms, glycosylation defective mutants, solid-phase cell adhesion assay

\begin{abstract}
Carcinoembryonic antigen (CEA) is an oncofoetal cell surface glycoprotein that serves as an important tumour marker for colorectal and some other carcinomas. Its immunoglobulin-like structure places CEA within the immunoglobulin superfamily. CEA functions in several biological roles including homotypic and heterotypic (with other CEA family members) cell adhesion. Cell-cell interaction can be modulated by different factors, e.g., post-translational modifications such as glycosylation. The purpose of this study was to examine whether changes in carbohydrate composition of CEA oligosaccharides can influence homotypic (CEA-CEA) interactions. In order to modulate glycosylation of CEA we used two different glycosylation mutants of Chinese hamster ovary (CHO) cells, Lec2 and Lec8. Lec2 cells should produce CEA with nonsialylated $\mathrm{N}$-glycans, while Lec8 cells should yield more truncated sugar structures than Lec2. Parental CHO (Pro5) cells and the glycosylation deficient mutants were stably transfected with CEA cDNA. All three CEA glycoforms, tested in a solid-phase cell adhesion assay, showed an ability to mediate CEA-dependent cell adhesion, and no qualitative differences in the adhesion between the glycoforms were observed. Thus, it may be assumed that carbohydrates do not play a role in homotypic adhesion, and the interactions between CEA molecules depend solely on the polypeptide structure.
\end{abstract}

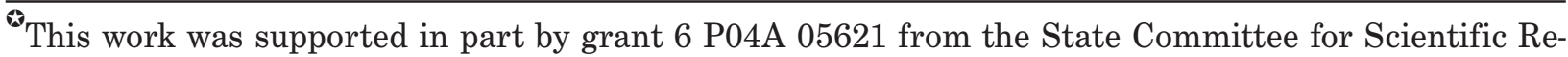
search (KBN, Poland).

${ }^{凶}$ To whom correspondence should be addressed: Anna Krop-Watorek, Department of Immunochemistry, Ludwik Hirszfeld Institute of Immunology and Experimental Therapy, Polish Academy of Sciences, Rudolfa Weigla 12, 53-114 Wrocław, Poland; phone: (48 71) 3732274 or (48 71) 373 2316, ext. 208, fax: (48 71) 373 2587; e-mail: krop@immuno.iitd.pan.wroc.pl
}

Abbreviations: CEA, carcinoembryonic antigen; CHO cells, Chinese hamster ovary cells; $\mathrm{PBS}^{(-)}$, phosphate-buffered saline lacking $\mathrm{Ca}^{+2}$ and $\mathrm{Mg}^{+2}$. 
Carcinoembryonic antigen (CEA) is an oncofoetal glycoprotein present in normal foetal gastrointestinal tissues and in some tumours of epithelial origin (Gold \& Freedman, 1965; Chu et al., 1972; Fritsche \& Mach, 1977; Nap et al., 1988; Jothy et al., 1993). The elevated levels observed in colon, lung, breast and ovarian adenocarcinomas in comparison with normal adult tissues suggest that CEA could play an important role in cancer progression and embryogenesis (von Kleist et al., 1986; Wagner et al., 1992; Eidelman et al., 1993; Jessup et al., 1999; Krop-Watorek et al., 1999).

The CEA molecule has an immunoglobulin (Ig)-like structure composed of a single $\mathrm{N}$-terminal IgV-like domain, and six internal (A1B1, A2B2, A3B3), IgC2 type-like domains (Beauchemin et al., 1987; Oikawa et al., 1987a; Schrewe et al., 1990). This places CEA among members of the immunoglobulin supergene family (IgSF) (Oikawa et al., 1987b; Zimmermann et al., 1987). Moreover, CEA is a cell surface molecule (Hefta et al., 1988; Takami et al., 1988) and functions in vitro as a homophilic (CEA-CEA) and heterophilic (CEA-CEA family members), calcium-independent, cell adhesion molecule (Benchimol et al., 1989; Oikawa et al., 1991; Zhou et al., 1993).

CEA is a glycoprotein more extensively glycosylated than other IgSF members. Its molecular mass of about $180 \mathrm{kDa}$ in $50-60 \%$ is attributed to carbohydrates (Coligan et al., 1976; Hammarström et al., 1975; Chandrasekaran et al., 1983). The amino-acid sequence of CEA contains 28 potential N-glycosylation sites (Paxton et al., 1987), most of which are occupied by oligosaccharide chains; CEA $\mathrm{N}$-glycans are mostly tetraantennary complex chains, accompanied by mono-, di- and triantennary oligosaccharide structures, and by approx. $10 \%$ of high-mannose chains. The antennae of complex chains are composed primarily of repeating (-3Gal $\beta 1-4 \mathrm{GlcNAc} \beta 1-)$ units. Some of the N-glycans are sialylated on the nonreducing terminal galactose residues and/or contain sulfate groups (Yamashita et $a l .$, 1987). In CEA preparations of various origins considerable differences in the carbohydrate composition and oligosaccharide structures have been shown (Chandrasekaran et al., 1983; Garcia et al., 1991; Fukushima et al., 1995). However, the biological significance of this heterogeneity remains unknown.

The oligosaccharide chains of many cell surface glycoproteins are directly involved in recognition phenomena, including intracellular targeting, interactions with other cells and circulating proteins, reactions with anti-carbohydrate antibodies and binding of micro-organisms (Boehm et al., 1996; Feizi, 1994; Fieger et al., 2000; Wyss et al., 1995; Rudd et $a l ., 1999)$. Moreover, glycosylation may modulate interactions dependent on the polypeptide chain. For example, a neural cell adhesion molecule has been reported to show enhanced adhesion with decreased polysialylation (Hoffman \& Edelman, 1983) and the intercellular adhesion molecule 1 with a truncated carbohydrate structure shows increased adhesion to the Mac-1 integrin (Diamond et al., 1991). It is known that defined fragments of the CEA polypeptide chain are involved in CEA-CEA interaction (Zhou et al., 1993; Boehm et al., 1996; Taheri et al., 2000). However, the question remains whether modified CEA oligosaccharide chains may affect the CEA-related homotypic adhesion.

In order to study the role of glycosylation it is useful to compare the same protein at different glycosylation levels. One approach to obtain stable glycosylation variants is to express the protein in cells with defined glycosylation defects. The aim of this report is to examine whether changes in glycosylation of CEA affect its homophilic cell adhesion. To this end, using a solid phase cell adhesion assay, we tested stably expressed CEA in wild-type Chinese hamster ovary (CHO) cells (C5 and Pro5) and in glycosylation-defective variants of CHO cells (Lec2 and Lec8). The Lec2 and Lec8 mutants are unable to transport CMP-sialic acid and UDP-galactose, respectively, into the Golgi compartment 
(Deutscher et al., 1984; Deutscher \& Hirschberg, 1986). Therefore, these cells should produce CEA glycoforms with nonsialylated (Lec2), or more truncated (Lec8) N-glycans.

To date, we are aware of only one other attempt to study the role of oligosaccharide chains in CEA homotypic cell adhesion (Charbonneau \& Stanners, 1999). These authors concluded that carbohydrates do not determine specificity of CEA adhesion, but taking into account the unusually high degree of glycosylation, they do not exclude modification of the strength of the adhesion. However, these conclusions were based on a cell aggregration assay in solution, while in our studies we used a solid-phase cell adhesion assay, which in our opinion is more accurate and better reflects the natural conditions occuring in tissues.

\section{MATERIALS AND METHODS}

\section{Cell lines and cell culture conditions.} Wild-type Chinese hamster ovary (CHO) cells (Pro5) and the glycosylation-defective mutants (Lec2 and Lec8) were obtained from the American Type Culture Collection (Rockville, MD, U.S.A.); C5 and CEA-expressing C5 cells, C5/CEA, were from Dr. Shinzo Oikawa (Institute for Biomedical Research, Suntory Ltd., Osaka, Japan). CHO cells were cultured in alpha-Minimal Essential Medium ( $\alpha$-MEM) supplemented with $10 \%$ foetal calf serum (FCS) (Gibco-BRL, Grand Island, NY, USA), $2 \mathrm{mM}$ glutamine, 100 units $/ \mathrm{ml}$ penicillin and 100 $\mu \mathrm{g} / \mathrm{ml}$ streptomycin (Sigma-Aldrich, Irvine, Great Britain). The cell cultures were maintained at $37^{\circ} \mathrm{C}$ in a humidified atmosphere at $5 \% \mathrm{CO}_{2}$ in air.

Transfection procedure and positive clone selection. For construction of stable transfectants, CHO Pro5, Lec2 and Lec8 cells $\left(1 \times 10^{6}\right)$ were co-transfected with $20 \mu \mathrm{g}$ of the eukaryotic expression vector pSG5CEA and $2 \mu \mathrm{g}$ of the pSV2neo plasmid by the
DNA-calcium phosphate precipitation method (Graham \& Van der Eb, 1973) using the Cell Phect Transfection Kit (Pharmacia, Sweden). The full-length cDNA of CEA was isolated from the pdKCR-neo plasmid, kindly provided by Dr. Shinzo Oikawa (Institute for Biomedical Research, Suntory Ltd., Osaka, Japan) (Oikawa et al., 1987a). Control cells were transfected with $2 \mu \mathrm{g}$ of the pSV2 neomycin-resistance plasmid only. After $48 \mathrm{~h}$ the medium was replaced with fresh complete $\alpha$-MEM medium containing $0.5 \mathrm{mg} / \mathrm{ml}$ of geneticin G418 (Gibco-BRL, Paisley, Scotland). The medium was replaced approximately every 2 days for 14 days. The neomycin-resistant colonies were isolated, cloned by limiting dilution, expanded, and screened for CEA expression by the fluorescence activated cell sorter assay and Western blotting.

Fluorescence activated cell sorter (FACS) assay. Cells were detached (from culture dish) with $0.2 \%$ EDTA in Hanks' balanced salt solution, $\mathrm{pH} 7.4$ and washed twice in a Tris/BSA (bovine serum albumin) buffer (50 $\mathrm{mM}$ Tris/HCl, 0.1\% BSA, $150 \mathrm{mM} \mathrm{NaCl}, \mathrm{pH}$ 7.8). Tris/BSA buffer at $4^{\circ} \mathrm{C}$ was used in all subsequent cell treatments as follows: cells $\left(0.5 \times 10^{6}\right)$ were incubated for $1 \mathrm{~h}$ with goat anti-CEA polyclonal antibody $(50 \mu \mathrm{g} / \mathrm{ml})$, washed three times, and incubated for an additional hour with fluorescein-isothiocyanate-conjugated rabbit $\mathrm{F}(\mathrm{ab})_{2}$ fragment of anti-goat Ig antibodies (1:100, Becton-Dickinson, San Jose, CA, U.S.A.). Labelled cells were washed, resuspended in $0.5 \mathrm{ml}$ Tris/BSA buffer and the intensity of fluorescence was measured using a FACScan flow cytometer (Becton-Dickinson, Mountain View, CA, U.S.A.) using WinMDI 2.0.4 software for data processing. Five thousand cells were acquired for each data file. Dead cells were detected by low forward and right angle scatter and excluded from the analysis.

Electrophoresis and Western blotting. Untransfected and CEA-expressing cells $(2 \times$ $10^{6}$ ) were solubilized in a lysis buffer $(50 \mathrm{mM}$ Tris/HCl, $\mathrm{pH}$ 8.0, containing $0.5 \%$ NP-40, 
$150 \mathrm{mM} \mathrm{NaCl}, 1 \mathrm{mM}$ EDTA, $1 \mathrm{mM}$ phenylmethylsulfonyl-fluoride, $2 \mu \mathrm{g} / \mathrm{ml}$ aprotinin and $2 \mu \mathrm{g} / \mathrm{ml}$ leupeptin) (Sigma, St. Louis, MO, U.S.A.), vigorously mixed by Vortex and after 15 min incubation on ice centrifuged at 20000 r.p.m. for $10 \mathrm{~min}$. The supernatants were analysed for protein concentration by the method of Lowry (Lowry et al., 1951) with bovine serum albumin as a standard. Samples containing $50 \mu \mathrm{g}$ of protein were separated by SDS/PAGE (Laemmli, 1970) using a 7.5\% gel. The electrophoretically separated proteins were transferred to nitrocellulose (Schleicher and Schuell, Dassel, Germany) (Towbin et al., 1979). The blots were blocked for $1 \mathrm{~h}$ with $1 \%$ casein in Tris-buffered saline (TBS; $50 \mathrm{mM}$ Tris/ $\mathrm{HCl}, 200 \mathrm{mM} \mathrm{NaCl}, \mathrm{pH}$ 7.5) and overlaid subsequently with polyclonal rabbit anti-CEA antibodies (1:500, Dako, Glostrup, Denmark) and with goat anti-rabbit immunoglobulins conjugated with phosphatase $(1: 500$, BioRad, Hercules, CA, U.S.A.). Following a $1 \mathrm{~h}$ incubation at room temperature, the blots were developed with phosphatase substrates: BCIP/NBT (5-bromo-4-chloro-3-indolyl phosphate/nitro blue tetrazolium) in 0.1 M AMP buffer (2-amino-2-methyl-1,3-propandiol) (Sigma, St. Louis, MO, U.S.A.) with $5 \mathrm{mM}$ $\mathrm{MgCl}_{2}, \mathrm{pH}$ 9.5. The following prestained electrophoretic standards (Bio-Rad, Hercules, CA, U.S.A.) were used: myosin, $194 \mathrm{kDa}$; $\beta$-galactosidase, $116 \mathrm{kDa}$; bovine serum albumin, $85 \mathrm{kDa}$; ovalbumin, $48 \mathrm{kDa}$.

Solid-phase cell adhesion assay. The cells for isotopic labelling were cultured in a $10 \mathrm{~cm}$ tissue culture dish (Falcon, Lincoln Park, NJ, U.S.A.), washed with $\alpha$-MEM and labelled with $\mathrm{Na}_{2}{ }^{51} \mathrm{CrO}_{4}$ (Centre of Isotopic Research, Polatom, Świerk, Poland) (100 $\mu \mathrm{Ci} / 1.5 \mathrm{ml}$ $\alpha$-MEM) for $2 \mathrm{~h}$ at $37^{\circ} \mathrm{C}$, washed once with medium and cultured in fresh $\alpha$-MEM for an additional hour. The ${ }^{51} \mathrm{Cr}$-labelled cells were then washed twice with phosphate-buffered saline lacking $\mathrm{Ca}^{+2}$ and $\mathrm{Mg}^{+2}$ (PBS ${ }^{(-)} ; 0.01 \mathrm{M}$ $\mathrm{NaH}_{2} \mathrm{PO}_{4} / \mathrm{Na}_{2} \mathrm{HPO}_{4}, 0.15 \mathrm{M} \mathrm{NaCl}, \mathrm{pH}$ 7.4), detached with $0.2 \%$ EDTA in $\mathrm{PBS}^{(-)}$, pelleted and resuspended in $3 \mathrm{ml} \alpha-\mathrm{MEM}$ by three passes through a 26-gauge needle and were added in $0.1 \mathrm{ml}$ aliquots/well to a monolayer of unlabelled cells cultured in $0.5 \mathrm{ml}$ of $\alpha$-MEM in 24-well tissue culture plates (Falcon, Lincoln Park, NJ, U.S.A.). The cells were allowed to adhere for $1 \mathrm{~h}$ at $37^{\circ} \mathrm{C}\left(5 \% \mathrm{CO}_{2}\right)$ and nonadherent cells were washed off twice with $\mathrm{PBS}^{(-)}$. The adherent cells were lysed in $1 \%$ NP-40 and the radioactivity was measured in a gamma-counter (Beckman Gamma-5500B, Palo Alto, CA, U.S.A.). Three independent cell adhesion assays were carried out in triplicate.

\section{RESULTS}

\section{Characterization of CEA expressed in wild type cells and the glycosylation mutants}

CEA was stably expressed in the wild type (Pro5) CHO cells and the glycosylation-defective mutants (Lec2 and Lec8) transfected with recombinant CEA cDNA. (The C5 CHO cells expressing CEA were used for comparison). The presence of CEA on the cell surface was evaluated by cytofluorimetric analysis using goat anti-CEA polyclonal antibodies. Subclones with the highest CEA expression (C5/CEA, Pro5/CEA 4.24, Lec2/CEA 12.14 and Lec8/CEA 11.1) were selected for further studies (Fig. 1). (For simplicity the numbers of the selected subclones are omitted in the text and in the figures). It had previously been shown that the Lec2 cells are defective in sialylation, while in the Lec8 cells galactosylation is inhibited (Deutscher et al., 1984; Deutscher \& Hirschberg, 1986). Thus, CEA expressed in these glycosylation mutants should contain truncated, instead of fully glycosylated, N-glycans (Fig. 2). Taking into account that over $50 \%$ of the CEA molecule consists of carbohydrates, the molecular masses of the CEA glycoforms expressed in Lec2 and Lec8 cells should be decreased. This was confirmed by SDS/PAGE and Western blotting analysis (Fig. 3). Untransfected control cells did not expressed CEA while all 


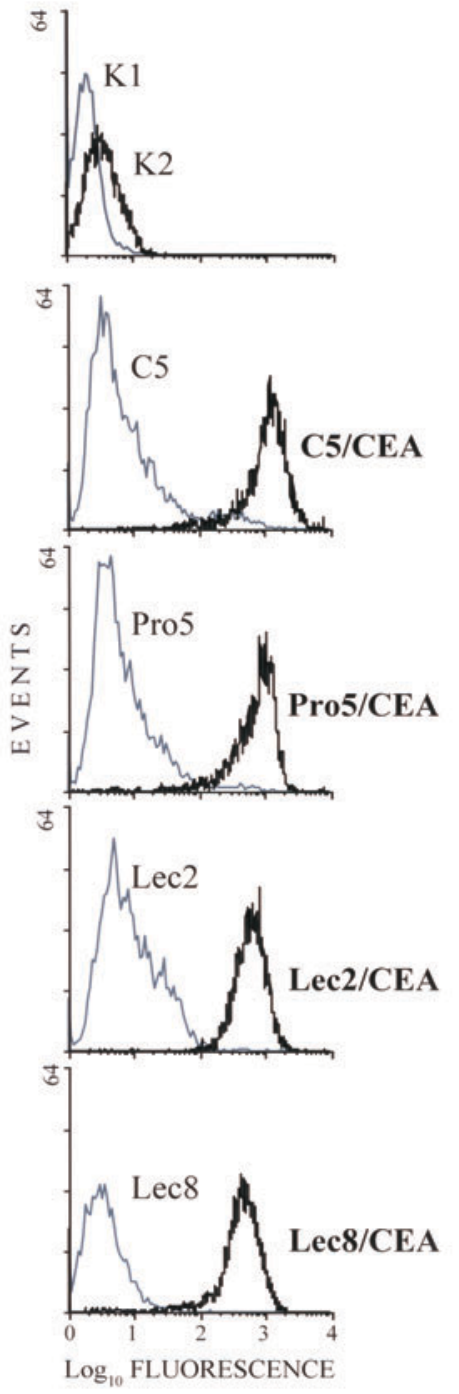

Figure 1. Flow cytofluorometric profiles of untransfected cells (C5, Pro5, Lec2 and Lec8) and their CEA cDNA transfectants.

$\mathrm{K} 1$ and $\mathrm{K} 2$ represent control cells treated respectively: with Tris/BSA buffer or with second antibody only. The cells $\left(0.5 \times 10^{6}\right)$ were incubated as described in Materials and Methods. The fluorescence intensity of the labelled cells was measured using a FACScan flow cytometer. Five thousand cells were acquired for each data file. The results shown are representative of four independent experiments.

types of transfected cells showed two major bands, as it is usually observed in CEA preparations obtained from different sources. This heterogeneity presumably results from the presence of high-mannose and less branched oligosaccharides instead of mature complex-type chains. The slowest-migrating bands of C5/CEA and Pro5/CEA cells, most likely representing the fully glycosylated CEA, corresponded to a molecular mass of about 180 $\mathrm{kDa}$, similar to that of CEA molecules isolated from the liver metastasis of colon adenocarcinoma (not shown). As expected, the CEA glycoforms synthesized by transfected Lec2 and Lec 8 cells migrated faster as about 160 $\mathrm{kDa}$ and about $140 \mathrm{kDa}$ molecules, respectively. Thus, the diminished molecular mass of CEA in Lec2/CEA and Lec8/CEA cells suggests that CEA synthesized in these glycosylation-defective mutants is underglycosylated.

\section{Adhesive properties of $\mathrm{CHO}$ cells express- ing fully glycosylated and underglycosylated CEA}

To examine whether incomplete glycosylation of CEA may influence its adhesive properties, a solid phase cell adhesion assay was performed (Fig. 4). All CEA transfectants tested (C5/CEA, Pro5/CEA, Lec2/CEA and Lec8/CEA) were able to adhere (50-70\%) to monolayers of all types of transfected cells (A). The adhesion levels of control cells, i.e., untransfected cells, to the monolayers of untransfected cells were below $30 \%$ (not shown). However, the adhesion levels of CEA-transfected cells to untransfected cells varied from $5 \%$ to $35 \%$ (B, CEA-independent adhesion); the real CEA-dependent adhesion levels (C) were obtained by subtracting these values (B) from total adhesion of CEA transfectants (A). Higher adhesion of the C5/CEA cells to all monolayers, compared with the adhesion of the remaining cell lines, was the most readily observable difference. Since the C5/CEA and Pro5/CEA cells expressed similarly glycosylated CEA (Fig. 3), the observed divergence of their adhesive properties may result from higher CEA expression in C5/CEA cells (Fig. 1). It is noteworthy that the CEA-unrelated adhesion of CEA transfectants to nontransfected cell monolayers was distinctly higher if at least one of the cell-types in the cell-cell interaction was Lec2 or Lec8 

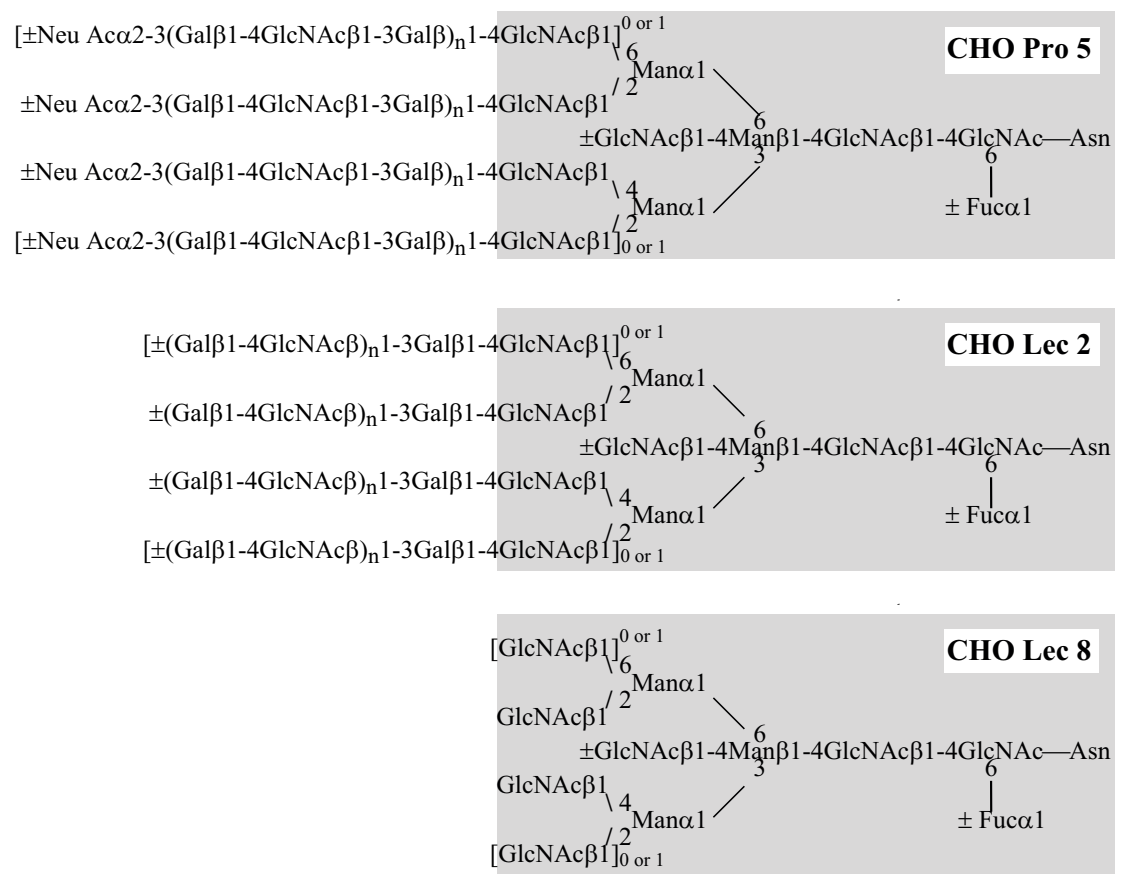

Figure 2. Putative structures of CEA complex N-glycans expressed in wild type CHO Pro5 and glycosylation-defective Lec2 and Lec8 cells.

The structures are based on data obtained with CEA from liver metastases of colorectal carcinoma (Yamashita et al., 1987). \pm Denotes that the residue may be either present or absent in this position. Shadowed boxes show the common oligosaccharide structure expressed on CHO Pro5, Lec2 and Lec8 cells.

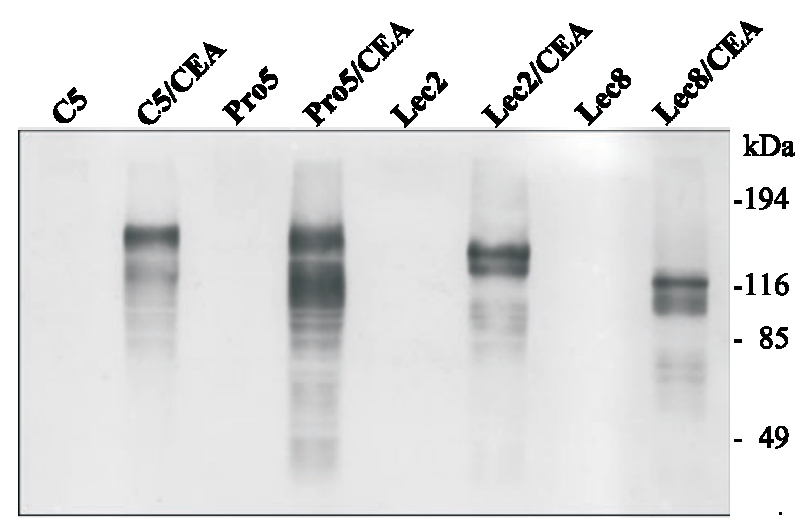

Figure 3. Immunoblot analysis of CEA expression in untransfected and CEA cDNA transfected CHO cells.

Cell lysates were fractionated by SDS/PAGE and immunoblotted as described in Materials and Methods. The apparent molecular mass of the protein standards are indicated on the right.

(Fig. 4B). Thus, it seems that truncated CEA oligosaccharide chains cause an increase of unspecific cell-cell interaction, while specific (i.e., CEA-related) cell adhesion remains unchanged. These data allow the conclusion to be drawn that sialic acid or galactose residues present on the CEA molecule have no influence on CEA-related homotypic cell adhesion.

\section{DISCUSSION}

CEA is a highly abundant cell surface glycoprotein mainly expressed on colonic epithelial cells in early embryonic and carcinoma stages. It functions as a calcium independent, homophilic cell adhesion molecule. Since sugar residues of some glycoproteins are involved in adhesion events (Hoffman \& Edelman, 1983; Diamond et al., 1991; Ono et al., 2000; Horstkorte et al., 2001) glycosylation of CEA could have important consequences in embryo- and carcinogenesis. The CEA molecule is heavily glycosylated (Yamashita et al., 1987) and it was shown that carbohydrate 

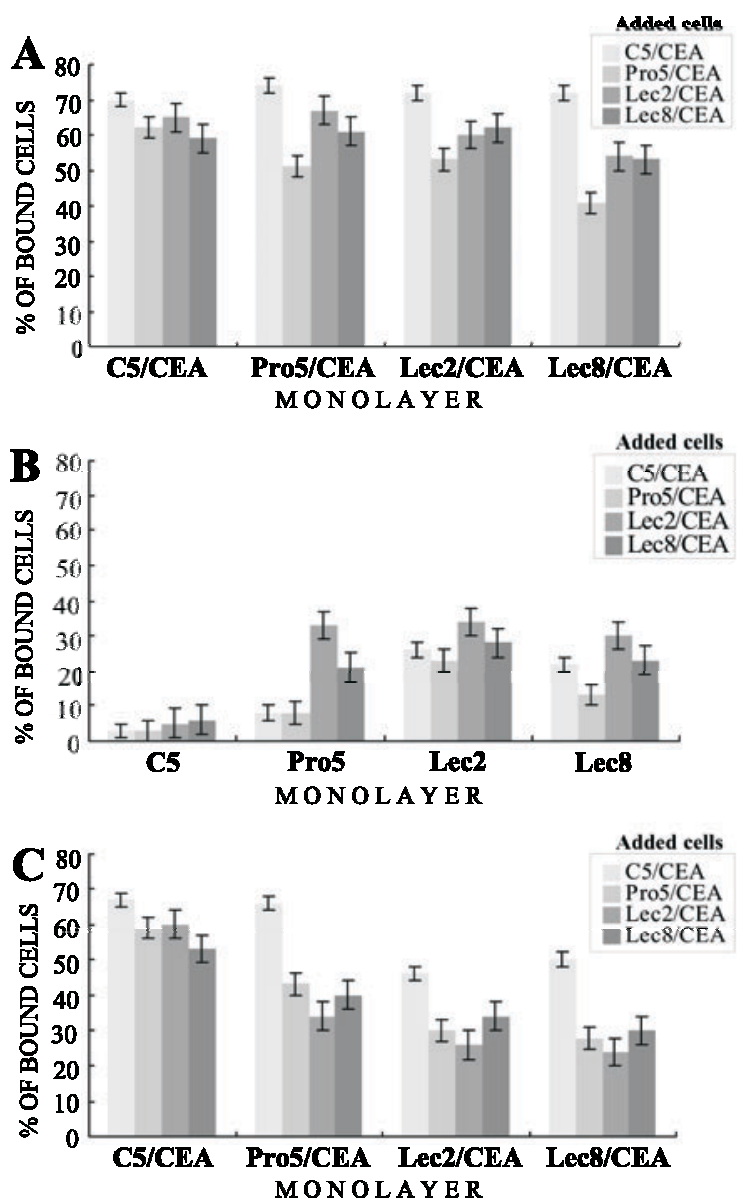

Figure 4. Solid-phase cell adhesion assay of fully glycosylated (C5 and Pro5) and underglycosylated (Lec2 and Lec8) CHO cells transfected with CEA cDNA.

(A) Adhesion of CEA transfectants to CEA transfectants monolayers, (B) adhesion of CEA transfectants to untransfected cells monolayers, (C) the difference between the adhesion of CEA transfectants to the monolayers of transfected (A) and untransfected cells (B). The adhesion assay was performed as described in Materials and Methods. Data represent the means of three replicates of three independent experiments. Standard deviation from triplicate assays are indicated at the top of each bar.

moieties of tumour CEA and its counterparts produced by colonic epithelial cells of normal adults (NFA-2) or foetuses (NCA-2) revealed differences induced by development and malignant transformation of normal epithelial cells (Yamashita et al., 1989; Wojciechowicz et $a l ., 2000)$.
To study a possible role of carbohydrate in CEA-CEA interaction, we prepared stable transfectants expressing CEA molecules in $\mathrm{CHO}$ glycosylation-defective mutant cell lines, Lec2 and Lec8. The expected deficiencies in glycosylation of CEA molecules synthesized in these cells were confirmed by a decrease in the molecular size of CEA in Lec2 and Lec8 cells (Fig. 3). The adhesive properties of CEA-expressing fully glycosylated and underglycosylated $\mathrm{CHO}$ cells were evaluated by a solid-phase cell adhesion assay. It was found that all tested types of cells expressing CEA glycoforms adhered to monolayers of CEA-expressing transfectants irrespective of their carbohydrate composition. It is noteworthy that CEA-unrelated adhesion of the fully glycosylated cells C5 and Pro5 was distinctly lower than adhesion of the mutant cells Lec2 and Lec8. This may suggest that truncated oligosaccharide chains promote an increase of CEA-unrelated adhesion. However, when CEA was present on the surface of both interacting cells, adhesion levels of all the cell lines tested were similar. In addition, in the mutant cell lines Lec2 and Lec8, other cell surface glycoproteins may also be underglycosylated. This may be a reason of increased "unspecific" interaction between these cells. Thus, these results allow us to conclude that the terminal sialic acid and $\mathrm{Gal} \beta 1-4 \mathrm{GlcNAc} \beta 1-3$ (Fig. 2) are not involved in homophilic CEA dependent cell adhesion.

Charbonneau and Stanners (1999) used CHO cells (wild type LR-73, parental Pro5 and its glycosylation mutants Lec2 and Lec8) transfected with a functional cDNA of CEA. In addition, Lec 1 cells, which are able to express only oligo-mannose chains, were also transfected. The adhesive properties of these cells were tested by an aggregation assay of cells in suspension and it was demonstrated, in agreement with our results, that all CEA glycoforms are able to mediate cell adhesion. While the Lec 1 and Lec2 transfectants showed an increased speed and final extent of aggregation, the Lec8 transfectants showed weaker aggre- 
gation than that of wild type transfectants. It is difficult to find a simple explanation why the Lec8 and Lec1 CEA transfectants, both carrying neutral $\mathrm{N}$-glycans of similar size, differ in adhesion.

Modulation of the binding activity of a polypeptide chain by glycosylation occurs even if the carbohydrates do not participate directly in the interaction. The effects of $\mathrm{N}$-glycans on glycoprotein biological functions cannot be generalized, as each glycoprotein, or even each active site, represents an individual case. Glycosylation may be required for the proper exposure or conformation of peptidic epitopes. A decrease of polypeptide reactivity by oligosaccharide chains may be caused not only by masking of the active sites, but also by alterations of the peptide conformation or flexibility. For example, it was shown that apparent "masking" of the antigenic epitope of the influenza virus hemagglutinin is independent of N-glycan size. However, reactivity of the antibodies was observed only after complete removal of the carbohydrate by digestion with peptide-N-glycosidase F (Munk et al., 1992). In the case of CEA, the hydrophobic interaction between CEA $\mathrm{N}$-domains (Kaplan et al., 1998) may be diminished or altered as a result of the presence of oligosaccharides. It is known that recombinant, nonglycosylated CEA N-domain expressed in Escherichia coli forms high molecular-mass oligomers in aqueous solutions (Krop-Watorek et al., 1998). Thus, it cannot be ruled out that complete deglycosylation would give a strong increase of CEA-CEA interaction, while truncation of $\mathrm{N}$-glycans gives only limited (Charbonneau \& Stanners, 1999) or negligible (our results) quantitative alterations in this interaction.

\section{R E F E R E N C E S}

Beauchemin, N., Benchimol, S., Cournoyer, D., Fuks, A. \& Stanners, C.P. (1987) Isolation and characterization of full-length functional
cDNA clones for human carcinoembryonic antigen. Mol. Cell. Biol. 7, 3221-3230.

Benchimol, S., Fuks, A., Jothy, S., Beauchemin, N., Shirota, K. \& Stanners, C.P. (1989) Carcinoembryonic antigen, a human tumor marker, functions as an intercellular adhesion molecule. Cell 57, 327-334.

Boehm, M.K., Mayans, M.O., Thornton, J.D., Begent, R.H.J., Keep, P.A. \& Perkins, S.J. (1996) Extended glycoprotein structure of the seven domains in human carcinoembryonic antigen by X-ray and neutron solution scattering and an automated curve fitting procedure: Implications for cellular adhesion. J. Mol. Biol. 259, 718-736.

Chandrasekaran, E.V., Davila, M., Nixon, D.V., Goldfarb, M. \& Mendicino, J. (1983) Isolation and structures of the oligosaccharide units of carcinoembryonic antigen. J. Biol. Chem. 258, 7213-7222.

Charbonneau, J. \& Stanners, C.P. (1999) Role of carbohydrate structures in CEA-mediated intercellular adhesion. Cell Adhes. Commun. 7, 233-244.

Chu, T.M., Reynoso, G. \& Hansen, H.J. (1972) Demonstration of carcinoembryonic antigen in normal human plasma. Nature 238, $152-153$.

Coligan, J.E., Pritchard, D.G., Schnute, W.C., Jr. \& Todd, C.W. (1976) Methylation analysis of the carbohydrate portion of carcinoembryonic antigen. Cancer Res. 36, 1915-1917.

Deutscher, S.L., Nuwayhid, N., Stanley, P., Briles, E.I. \& Hirschberg, C.B. (1984) Translocation across Golgi vesicle membranes: A CHO glycosylation mutant deficient in CMP-sialic acid transport. Cell 39, 295-299.

Deutscher, S.L. \& Hirschberg, C.B. (1986) Mechanism of galactosylation in the Golgi apparatus. J. Biol. Chem. 261, 96-100.

Diamond, M.S., Staunton, D.E., Marlin, S.D. \& Springer, T.A. (1991) Binding of the integrin Mac-1 (CD11b/CD18) to the third immunoglobulin-like domain of ICAM-1 (CD54) and its regulation by glycosylation. Cell 65, 961-971.

Eidelman, F.J., Fuks, A., DeMarte, L., Taheri, M. \& Stanners, C.P. (1993) Human carcino- 
embryonic antigen, an intercellular adhesion molecule, blocks fusion and differentiation of rat myoblasts. Cell Biol. 123, 467-475.

Feizi, J. (1994) Evidence for carbohydrate-mediated interactions between the neural cell adhesion molecules NCAM and L1. Trends Biochem. Sci. 19, 233-234.

Fieger, C.B., Emig-Vollmer, S., Petri, T., Grafe, M., Gohlke, M., Debus, N., Semmler, W., Tauber, R. \& Volz, B. (2000) The adhesion properties of recombinant soluble L-selectin are modulated by its glycosylation. Biochim. Biophys. Acta 1524, 75-85.

Fritsche, R. \& Mach, J.-P. (1977) Isolation and characterization of carcinoembryonic antigen (CEA) extracted from normal human colon mucosa. Immunochemistry 14, 119-127.

Fukushima, K., Ohkura, T., Kanai, M., Kuroki, M., Matsuoka, Y., Kobata, A. \& Yamashita, K. (1995) Carbohydrate structures of a normal counterpart of the carcinoembryonic antigen produced by colon epithelial cells of normal adults. Glycobiology 5, 105-115.

Garcia, M., Seigner, C., Bastid, C., Choux, R., Payan, M.J. \& Reggio, H. (1991) Carcinoembryonic antigen has a different molecular weight in normal colon and in cancer cells due to N-glycosylation differences. Cancer Res. 51, 5679-5686.

Gold, P. \& Freedman, S.O. (1965) Specific carcinoembryonic antigens of the human digestive system. J. Exp. Med. 122, 467-485.

Graham, F.L. \& Van der Eb, A.J. (1973) A new technique for the assay of infectivity of human adenovirus 5 DNA. Virology 52, 456-467.

Hammarström, S., Engvall, E., Johansson, B.G., Svensson, S., Sundblad, G. \& Goldstein, I.J. (1975) Nature of the tumor-associated determinant(s) of carcinoembryonic antigen. Proc. Natl. Acad. Sci. U.S.A. 72, 1528-1532.

Hefta, S.A., Hefta, L.J.F., Lee, T.D., Paxton, R.J. \& Shively, J.E. (1988) Carcinoembryonic antigen is anchored to membranes by covalent attachment to a glycosylphosphatidylinositol moiety: Identification of the ethanolamine linkage site. Proc. Natl. Acad. Sci. U.S.A. 85, 46484652.
Hoffman, S. \& Edelman, G.M. (1983) Kinetics of homophilic binding by $\mathrm{E}$ and $\mathrm{A}$ forms of the neural cell adhesion molecule. Proc. Natl. Acad. Sci. U.S.A. 80, 5762-5766.

Horstkorte, R., Lee, H.Y., Lucka, L., Danker, K., Mantey, L. \& Reutter, W. (2001) Biochemical engineering of the side chain of sialic acids increases the biological stability of the highly sialylated cell adhesion molecule CEACAM1. Biochem. Biophys. Res. Commun. 283, 31-35.

Jessup, J.M., Ishii, S., Mitzoi, T., Edmiston, K.H. \& Shoji, Y. (1999) Carcinoembryonic antigen facilitates experimental metastasis through a mechanism that does not involve adhesion to liver cells. Clin. Exp. Metastasis 17, 481-488.

Jothy, S., Yuan, S.-Y. \& Shirota, K. (1993) Transcription of carcinoembryonic antigen in normal colon and colon carcinoma. Am. J. Pathol. 143, 250-257.

Kaplan, B.E., Hefta, L.J., Blake II, R.C., Swiderek, K.M. \& Shively, J.E. (1998) Solid-phase synthesis and characterization of carcinoembryonic antigen (CEA) domains. J. Peptide Res. 52, 249-260.

Krop-Watorek, A., Oikawa, S., Oyama, Y. \& Nakazato, H. (1998) Oligomerization of $\mathrm{N}$-terminal domain of carcinoembryonic antigen (CEA), expressed in Escherichia coli. Biochem. Biophys. Res. Commun. 242, 79-83.

Krop-Watorek, A., Laskowska, A., Salwa, J., Klopocki, A.G., Grunert, F. \& Ugorski, M. (1999) CEA-related proteins on human urothelial cell lines of different transformation grades. Cancer Lett. 139, 15-22.

Laemmli, U.K. (1970) Cleavage of structural proteins during the assembly of the head of bacteriophage T4. Nature 227, 680-685.

Lowry, O.H., Rosebrough, N.J., Farr, A.I. \& Randall, R.I. (1951) Protein measurement with the Folin phenol reagent. J. Biol. Chem. 193, 265-275.

Munk, K., Pritzer, E., Kretzschmar, E., Gutte, B., Garten, W. \& Klenk, H.D. (1992) Carbohydrate masking of an antigenic epitope of influenza virus haemagglutinin independent of oligosaccharide size. Glycobiology 2, 233-240. 
Nap, M., Mollgard, K., Burtin, P. \& Fleuren, G.J. (1988) Immunohistochemistry of carcino-embryonic antigen in the embryo, fetus and adult. Tumor Biol. 9, 145-153.

Oikawa, S., Nakazato, H. \& Kosaki, G. (1987a) Primary structure of human carcinoembryonic antigen (CEA) deduced from cDNA sequence. Biochem. Biophys. Res. Commun. 142, 511-518.

Oikawa, S., Imajo, S., Noguchi, T., Kosaki, G. \& Nakazato, H. (1987b) The carcinoembryonic antigen (CEA) contains multiple immunoglobulin-like domains. Biochem. Biophys. Res. Commun. 144, 634-642.

Oikawa, S., Inuzuka, C., Kuroki, Mo., Arakawa, F., Matsuoka, Y., Kosaki, G. \& Nakazato, H. (1991) A specific heterotypic cell adhesion activity between members of carcinoembryonic antigen family, W272 and NCA, is mediated by N-domains. J. Biol. Chem. 266, 7995-8001.

Ono, M., Handa, K., Withers, D.A. \& Hakomori, S. (2000) Glycosylation effect on membrane domain (GEM) involved in cell adhesion and motility: A preliminary note on functional $\alpha 3$, $\alpha 5$-CD82 glycosylation complex in ldlD 14 cells. Biochem. Biophys. Res. Commun. 279, $744-750$.

Paxton, R.J., Mooser, G., Pande, H., Lee, T.D. \& Shively, J.E. (1987) Sequence analysis of carcinoembryonic antigen: Identification of glycosylation sites and homology with the immunoglobulins supergene family. Proc. Natl. Acad. Sci. U.S.A. 84, 920-924.

Rudd, P.M., Wormald, M.R., Stanfield, R.L., Huang, M., Mattsson, N., Speir, J.A., DiGennaro, J.A., Fetrow, J.S., Dwek, R.A. \& Wilson, I.A. (1999) Roles for glycosylation of cell surface receptors involved in cellular immune recognition. J. Mol. Biol. 293, 351-366.

Schrewe, H., Thompson, J., Bona, M., Hefta, L.J.F., Maruya, A., Hassauer, M., Shively, J.E., von Kleist, S. \& Zimmermann, W. (1990) Cloning of the complete gene for carcinoembryonic antigen: Analysis of its promoter indicates a region conveying cell type-specific expression. Mol. Cell. Biol. 10, 2738-2748.

Taheri, M., Saragovi, U., Fuks, A., Makkerh, J., Mort, J. \& Stanners, C.P. (2000) Self recogni- tion in the Ig superfamily - Identification of precise subdomains in carcinoembryonic antigen required for intercellular adhesion. $J$. Biol. Chem. 275, 26935-26943.

Takami, N., Misumi, Y., Kuroki, M., Matsuoka, Y. \& Ikehara, Y. (1988) Evidence for carboxyl-terminal processing and glycolipid-anchoring of human carcinoembryonic antigen. J. Biol. Chem. 263, 12716-12720.

Towbin, H., Staehelin, T. \& Gordon, J. (1979) Electrophoretic transfer of proteins from polyacrylamide gels to nitrocellulose sheets: Procedure and some applications. Proc. Natl. Acad. Sci. U.S.A. 76, 4350-4354.

Von Kleist, S., Winkler, J., Migule, I. \& Böhm, N. (1986) Carcinoembryonic antigen (CEA) in early embryogenesis: A study of the first trimestre of gestation. Anticancer Res. 6, 1265-1272.

Wagner, H.E., Toth, C.A., Steele, G.D. \& Thomas, P. (1992) Metastatic potential of human colon cancer cell lines: Relationship to cellular differentiation and carcinoembryonic antigen production. Clin. Exp. Metastasis 10, 25-31.

Wojciechowicz, D.C., Park, P.Y., Datta, R.V. \& Paty, P.B. (2000) CEA is the major PHA-L-reactive glycoprotein in colon carcinoma cell lines and tumors: Relationship between K-ras activation and beta 1-6 branching of N-linked carbohydrate on CEA. Biochem. Biophys. Res. Commun. 273, 147-153.

Wyss, D.F., Choi, J.S., Li, J., Knoppers, M.H., Willis, K.J., Arulanandum, A.R.N., Smolyar, A., Reinherz, E.L. \& Wagner, G. (1995) Conformation and function of the N-linked glycan in the adhesion domain of human CD2. Science $\mathbf{2 6 9}$, 1273-1278.

Yamashita, K., Totani, K., Kuroki, M., Matsuoka, Y., Ueda, I. \& Kobata, A. (1987) Structural studies of the carbohydrate moieties of carcinoembryonic antigens. Cancer Res. 47, $3451-3459$.

Yamashita, K., Totani, K., Iwaki, Y., Kuroki, M., Matsuoka, Y., Endo, T. \& Kobata, A. (1989) Carbohydrate structures of nonspecific crossreacting antigen-2, a glycoprotein purified from meconium as an antigen cross-reacting 
with anticarcinoembryonic antigen antibody. J. Biol. Chem. 264, 17873-17881.

Zhou, H., Fuks, A., Alcaraz, G., Bolling, T.J. \& Stanners, C.P. (1993) Homophilic adhesion between Ig superfamily carcinoembryonic antigen molecules involves double reciprocal bonds. Cell Biol. 122, 951-960.
Zimmermann, W., Ortlieb, B., Friedrich, R. \& von Kleist, S (1987) Isolation and characterization of cDNA clones encoding the human carcinoembryonic antigen reveal a highly conserved repeating structure. Proc. Natl. Acad. Sci. U.S.A. 84, 2960-2964. 